\title{
Produtividade de vinagreira, pimenta rosa e carobinha cultivadas em sucessão a mucuna preta e feijão de porco
}

\author{
MOREIRA, D.G.'; VIEIRA, M.C. ${ }^{*}$, HEREDIA ZÁRATE, N.A. '; CARNEVALI, T.O.'; TORALES, E.P. '; TABALDI, \\ L.A.2; LOURENTE, E.R.P.'; MERCANTE, F.M. ${ }^{3}$ \\ 1Universidade Federal da Grande Dourados, Caixa Postal 533, CEP: 79.804-970, Dourados-MS, Brasil; \\ ¿Universidade Federal de Santa Maria, Avenida Roraima, 1000, Camobil, CEP: 97.110-9709, Santa Maria-RS, \\ Brasil; 'Embrapa Agropecuária Oeste, Rodovia BR 163, s/n, Zona Rural, CEP: 79804-970, Dourados-MS, Brasil \\ *Autor para correspondência: mariavieira@ufgd.edu.br
}

\begin{abstract}
RESUMO: O uso de adubos verdes e/ou de plantas de cobertura é uma técnica que vem sendo difundida para o cultivo de espécies medicinais, por garantir a sustentabilidade do solo agrícola, ser flexível em seu uso e por melhorar a atividade biológica do solo. O objetivo do trabalho foi avaliar o uso de culturas de cobertura para incrementar a produção de massa de plantas de vinagreira, pimenta rosa e carobinha. Foram avaliadas duas espécies de leguminosas tropicais (mucuna preta e feijão de porco) como cobertura do solo e uma testemunha (sem cultura de cobertura) e três espécies medicinais (vinagreira, pimenta rosa e carobinha). O experimento foi arranjado em esquema de parcelas subdivididas, tendo nas parcelas as coberturas vegetais $e$ nas subparcelas, as plantas medicinais. As plantas para a cobertura vegetal foram propagadas por semeadura direta no local de cultivo, enquanto as medicinais foram transplantadas diretamente entre a palhada da cobertura vegetal. A produção da mucuna preta foi de $8,37 \mathrm{t}$ ha-1 de massa seca e do feijão de porco, de 14,37 tha-1 de massa seca. $\mathrm{O}$ uso das culturas de cobertura contribuiu para uma maior biomassa microbiana do solo. As produções de massas frescas de folhas, caules e frutos de vinagreira e de frutos da pimenta rosa foram maiores quando cultivadas em sucessão às coberturas vegetais do solo, independente da espécie. As produções da carobinha foram semelhantes quando cultivadas em áreas com ou sem a cobertura. Visando à maior produtividade da vinagreira e pimenta rosa, são indicadas as culturas antecessoras feijão de porco e mucuna preta.
\end{abstract}

Palavras-chave: plantas medicinais, Hibiscus sabdariffa, Schinus terebinthifolius, Jacaranda decurrens Cham. subsp. symmetrifoliolata.

\begin{abstract}
Productivity of roselle, Brazilian peppertree, and carobinha grown in succession to black velvet bean and jack bean. The use of green manure and/or cover crops is a technique that has been widespread for the cultivation of medicinal species, since it ensures the sustainability of agricultural soil, is flexible in its use, and improves biological activity in the soil. The purpose of this study was to evaluate the use of cover crops to increase biomass production of roselle, Brazilian peppertree, and carobinha plants. Two species of tropical legumes (black velvet bean and jack bean) were evaluated as ground covers, and also assessed were one control plot (without cover crops) and three medicinal species (roselle, Brazilian peppertree, and carobinha). The experiment was arranged in a split-plot design, where the plots had cover crops and the subplots contained the medicinal plants. The plants for the cover crop were propagated by direct sowing in the growing site, while the medicinal ones were transplanted directly between the cover crop. The dry mass production of the velvet beans and jack beans were $8.37 \mathrm{t}$ ha- 1 and $14.37 \mathrm{t}$, respectively. The use of cover crops contributed to the increased microbial biomass of the soil. The production of dry mass of leaves, stems, and fruits of roselle and fruits of Brazilian peppertree were higher when grown in succession to the crop cover for the soil, regardless of the species. The production of carobinha was similar when grown in areas with or without the cover. To increase the yield of roselle and Brazilian peppertree, preceding crops of jack bean and black velvet bean are recommended.
\end{abstract}

Keywords: medicinal plants, Hibiscus sabdariffa, Schinus terebinthifolius, Jacaranda decurrens Cham. subsp. symmetrifoliolata.

Recebido para publicação em 22/04/2015

Aceito para publicação em 23/02/2016

10.1590/1983-084X/15_085

Rev. Bras. PI. Med., Campinas, v.18, n.1, supl. I, p.326-335, 2016. 


\section{INTRODUÇÃO}

O Brasil detém a maior diversidade biológica do planeta, contando com rica flora, despertando interesses de comunidades científicas para o estudo, conservação e utilização racional desses recursos (Joly et al., 2011). Uma das técnicas mais efetivas para a preservação da diversidade é a conservação ex situ e o cultivo. Tendo como referencial esta afirmação temos bases suficientes para se justificar estudos de cunho agronômico com espécies que detém enorme potencial para uso em arranjos produtivos.

Dentre as plantas de interesse medicinal e presentes na lista do Ministério da Saúde com prioridade para estudos e possibilidade de uso no SUS (Sistema Único de Saúde) está a Schinus terebinthifolius Raddi (Anacardiaceae, pimenta rosa). Árvore nativa do Brasil que apresenta atividades comprovadas pela literatura como antifúngica (Santos et al., 2010a), antibacteriana e antiaderente (Freires et al., 2010) e eficiente no tratamento de sintomas dispépticos em pacientes com gastrite e na erradicação do Helicobacter pylori (Santos et al., 2010b).

Dentre as espécies que vêm sendo colhidas predatoriamente pela população, e que podem ser extintas, sem que seja esclarecida a sua eficácia medicinal, está o Jacaranda decurrens Cham. subsp. symmetrifoliolata (Bignoniaceae, carobinha). Esse subarbusto endêmico do Cerrado (Farias \& Proença, 2003) encontra-se em risco de extinção, devido principalmente à expansão do uso da terra (Bertoni et al., 2010) e pelas propriedades medicinais das suas raízes como antioxidante (Carvalho et al., 2009), antibacteriana (Zatta et al., 2009) e antifúngica (Fenner et al., 2006).

Ainda temos o Hibiscus sabdariffa L. (Malvaceae, vinagreira), originária da Ásia e África, que se adaptou perfeitamente em diferentes regiões do Brasil. Produz flores e folhas muito utilizadas como fonte para confecção de produtos fitoterápicos e alimentícios, sendo as flores boa fonte de vitaminas $A, B$ e $C$, de cálcio, ferro, fósforo e aminoácidos (Freitas et al., 2013). As folhas e flores apresentam efeitos terapêuticos como antioxidantes (Ramos et al., 2011) e antibacterianas (Maciel et al., 2012).

Uma técnica que vem sendo difundida e utilizada para o cultivo de espécies convencionais é o uso de adubos verdes e/ou de plantas de cobertura, que tem por finalidade principal garantir a sustentabilidade do solo agrícola, sendo, desta maneira, técnica que detém potencial para ser utilizada em arranjos agronômicos de cultivos de espécies medicinais. Esta técnica também nos proporciona bastante flexibilidade em seu uso, podendo os adubos verdes, serem incorporados ou não ao solo, serem rotacionados com a cultura de interesse, ou ainda em sucessão ou consórcio (Teodoro et al., 2011).

A palhada da cobertura vegetal protege o solo da radiação solar e previne a evaporação, reduzindo a taxa de evapotranspiração das culturas e proporcionando aumento no intervalo entre irrigações. Além disso, contribui na melhoria dos atributos físicos, químicos e biológicos do solo (Lima Filho et al., 2014). Dentre as Fabaceae mais usadas como adubo verde e cobertura vegetal estão a Stizolobium aterrimum Piper \& Tracy (mucuna preta) e a Canavalia ensiformis L. DC. (feijão de porco) (Teodoro et al., 2011). A mucuna preta e o feijão de porco apresentam desenvolvimento vegetativo eficiente e acentuada rusticidade, adaptandose bem às condições de deficiência hídrica e de temperaturas altas, o que as tem tornado as principais culturas utilizadas na adubação verde no Brasil (Tavares Junior et al., 2015).

Em áreas de Cerrado, no que se refere à cobertura do solo, o feijão de porco contribui para a redução da fitomassa das plantas espontâneas. A mucuna preta e feijão de porco também se destacam no incremento de macronutrientes e aumento da matéria orgânica sobre o solo (Teodoro et al., 2011). $O$ uso de coberturas vegetais também influencia nos atributos do solo melhorando a atividade biológica (Gomes et al., 2015).

Um solo de qualidade possui atividade biológica intensa e contém populações microbianas balanceadas. $O$ fato de muitos microrganismos utilizarem a fração disponível da matéria orgânica os faz sensíveis às mudanças na sua qualidade. Desta forma, a mensuração do carbono(C) da biomassa microbiana é um importante indicador de mudanças na química do solo e possibilita o monitoramento da relação entre química do solo e vegetação de cobertura. Assim o carbono da biomassa microbiana pode atuar como um indicador ambiental (Galon et al., 2014).

Além das melhorias citadas, o uso de cobertura vegetal pode incrementar a produção da cultura de interesse econômico. Silva et al. (2008) relatam que com o uso de coberturas vegetais antecedendo à cultura do milho, houve aumentou do rendimento de grãos. No entanto, esse resultado pode variar com a espécie em estudo ou com as variações das condições climáticas.

Em função do exposto, este estudo teve como objetivo avaliar o uso de cobertura vegetal com mucuna preta e feijão de porco sobre atributos microbiológicos do solo, produção de massa seca e produtividade de vinagreira, pimenta rosa e carobinha.

Rev. Bras. PI. Med., Campinas, v.18, n.1, supl. I, p.326-335, 2016. 


\section{MATERIAL E MÉTODOS}

O trabalho foi desenvolvido em campo, em Dourados-MS (22 $11^{\circ} 43.7^{\prime \prime} \mathrm{S}, 054^{\circ} 56^{\prime} 08.5^{\prime \prime} \mathrm{W}$ e altitude média de $463 \mathrm{~m}$ ), desde setembro de 2010 a dezembro de 2012. O clima da região é do tipo Aw (Kottek et al., 2006). As temperaturas máximas e mínimas e precipitações durante a condução do experimento estão dispostos na Figura 1.

Foram avaliadas duas espécies de leguminosas tropicais (mucuna preta e feijão-deporco) como cobertura do solo e uma testemunha (sem cultura de cobertura) e três espécies medicinais: vinagreira, pimenta rosa e carobinha como culturas sucessoras. As parcelas tiveram área útil de $10 \mathrm{~m}^{2}$, sendo 5,0 $\mathrm{m}$ de comprimento por 2,0 $\mathrm{m}$ de largura.

O experimento foi conduzido em Latossolo Vermelho distroférrico, originalmente sob vegetação de Cerrado, de textura muito argilosa e topografia plana. Os atributos do solo antes do transplante foram determinados segundo a metodologia de Silva et al. (2009): $\mathrm{pH}$ em água $=5,1 ; \mathrm{P}=10,9 \mathrm{mg}$ $\mathrm{dm}^{-3} ; \mathrm{Ca}=2,3 \mathrm{cmol}_{\mathrm{c}} \mathrm{dm}^{-3} ; \mathrm{K}=2,4 \mathrm{cmol}_{\mathrm{c}} \mathrm{dm}^{-3} ; \mathrm{Mg}^{2}=1,7$ $\mathrm{cmol}_{\mathrm{c}} \mathrm{dm}^{-3} ; \mathrm{Al}=5,5 \mathrm{cmol}_{\mathrm{c}} \mathrm{dm}^{-3} ; \mathrm{SB}=4,4 \mathrm{cmol}_{\mathrm{c}} \mathrm{dm}^{-3}$; $\mathrm{T}=10,9 \mathrm{cmol}_{\mathrm{c}} \mathrm{dm}^{-3}$ e V\%= 40,0 e matéria orgânica= $20,3 \mathrm{~g} \mathrm{~kg}^{-1}$.

As plantas para a cobertura vegetal foram semeadas em setembro de 2010 , diretamente no local definitivo, em quatro fileiras, espaçadas de 0,50 $\mathrm{m}$. Para a mucuna preta, a densidade de semeio foi de 10 plantas $\mathrm{m}^{-2}$ (100.000 plantas ha-1) e para o feijão de porco, de 4 plantas $m^{-2}$ (40.000 plantas ha-1). Aos 120 dias após o semeio (DAS), em janeiro de 2011, no florescimento, foi coletado material de 1,0 $\mathrm{m}^{2}$ de cada parcela, para determinação da massa fresca e seca e em seguida, a cobertura vegetal foi cortada rente ao solo e deixada na superfície do mesmo.

Para a propagação das plantas medicinais, usaram-se sementes colhidas aleatoriamente em plantas de populações naturais (Autorização de Acesso e de Remessa de Amostra de Componente do Patrimônio Genético n 010220/2015-1 - CNPq/ CGEN/MMA), em agosto de 2010. As espécies foram identificadas e uma exsicata de cada uma delas está depositada no Herbário da Universidade Federal da Grande Dourados (DDMS), sob os respectivos números: Jacaranda decurrens Cham. subsp. symmetrifoliolata (2322), Hibiscus sabdariffa L. (1710) e Schinus terebinthifolius Raddi (4602).

A semeadura das plantas medicinais foi feita em setembro de 2010 (carobinha) e novembro de 2010 (vinagreira e pimenta rosa) em bandejas de poliestireno de 128 células preenchidas com substrato comercial Bioplant $₫$, e mantidas em ambiente protegido com $50 \%$ de sombreamento e irrigações diárias. O transplante ao campo ocorreu quando as plântulas atingiram cerca de $10 \mathrm{~cm}$ de altura, o que ocorreu aos 60 dias após o semeio para vinagreira e pimenta-rosa e 120 dias para a carobinha, aos 20 dias após o corte das plantas de

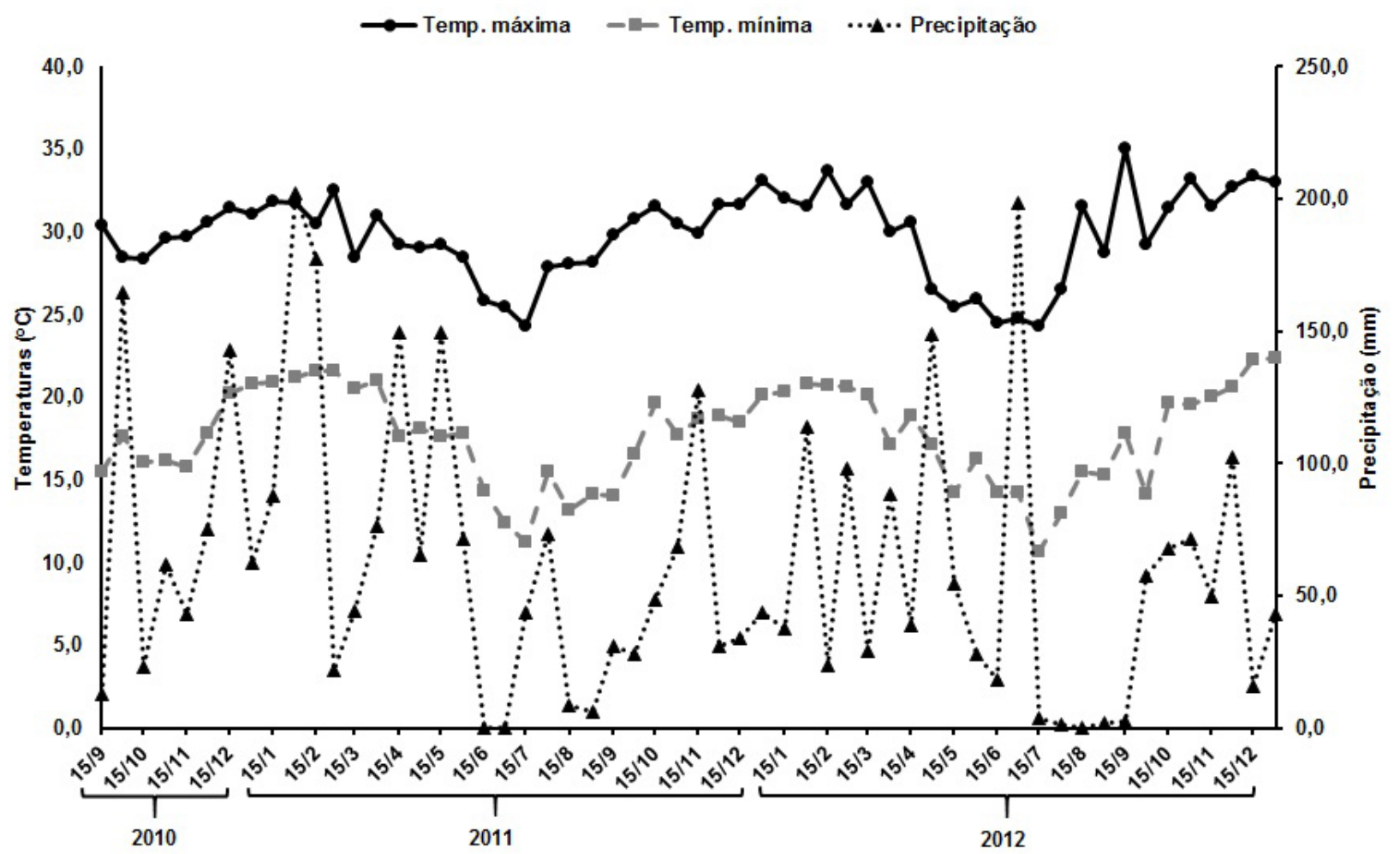

FIGURA 1. Precipitações e temperaturas máximas e mínimas, durante o ciclo de cultivo das coberturas vegetais e das plantas sucessoras. Dourados - 2010/2012.

Rev. Bras. PI. Med., Campinas, v.18, n.1, supl. I, p.326-335, 2016. 
cobertura, entre a palhada, bem como na parcela testemunha. Os espaçamentos utilizados para as plantas medicinais foram de $0,50 \mathrm{~m}$ entre plantas e 1,0 m entre fileiras, resultando em população de 20.000 plantas ha-1. $^{-1}$

Os tratos culturais compreenderam irrigações pelo sistema de aspersão sempre que necessário. Como não houve incidência de fitopatógenos e de pragas durante a cultivo das coberturas nem das plantas medicinais, não foi necessário controle. O controle de plantas espontâneas foi realizado por capinas com enxadas entre as fileiras e manualmente dentro das fileiras.

Durante o ciclo de cultivo das plantas medicinais, foram medidas as alturas de todas as plantas nas subparcelas a cada 30 dias, sendo o número de avaliações variável com o ciclo de cada cultura: para pimenta rosa, até 490 dias após o transplante (DAT); para carobinha, até 420 DAT e para a vinagreira, até 180 DAT.

Quando as plantas da vinagreira começaram a florescer, aos 78 DAT, foram colhidas quatro de cada subparcela, cortando-as rente ao solo. Depois, foram separados os caules e folhas para determinação das áreas foliares, usando analisador de imagens Windias 3 (Windias, Delta-T Devices, Cambridge, UK), e massas secas dos órgãos. Das plantas remanescentes de cada parcela, foi avaliada a massa seca dos cálices, colhidos aos 99, 117 e 140 DAT, usando como indicativo do ponto de colheita o comprimento mínimo de $3,5 \mathrm{~cm}$. Depois, obteve-se a soma da massa seca.

Das plantas de pimenta rosa foram colhidos os frutos, escalonadamente, desde 365 até 420 DAT, usando como indicativo do ponto de colheita a coloração rosa-avermelhada. Depois, obteve-se a soma da produção de massa seca dos frutos. Aos 545 DAT, foram cortados todos os ramos das plantas (exceto o tronco principal) para avaliação das áreas foliares e massas secas de caules e folhas.

As plantas de carobinha foram colhidas inteiras, aos 560 DAT. Foram avaliadas as áreas foliares e massas secas de folhas, caules, rizóforos e raízes.

Para obtenção das massas secas, o material de cada parte das plantas, de cada uma das três espécies, foi colocado em sacos de papel, acondicionados em estufa com circulação forçada de ar, a $60^{\circ} \pm 5^{\circ} \mathrm{C}$, até massa constante.

A coleta de solo para análise microbiológica foi realizada na camada de 0,00-0,10 m em duas épocas, aos e 420 e 840 dias após semeio (DAS) das coberturas vegetais. A análise do carbono da biomassa microbiana do solo (C-BMS) foi feita pelo método da fumigação-extração, adotando-se fator de correção para eficiência de extração $\left(k_{e c}\right)$ de 0,33 (Vance et al., 1987); o C orgânico, pelo de
Mebius, modificado por Yeomans \& Bremner (1989); a respiração basal $\left(\mathrm{C}-\mathrm{CO}_{2}\right)$, pelo da respirometria (evolução de $\left.\mathrm{CO}_{2}\right)$ e o quociente metabólico $\left(q \mathrm{CO}_{2}\right)$, pela divisão dos valores da respiração basal pelo do carbono microbiano $\left(\mu \mathrm{CO}_{2} / \mu \mathrm{g} \mathrm{C}-\mathrm{BMS} \mathrm{h}^{-1}\right)$. As análises químicas do solo foram determinadas de acordo com metodologia descrita por Silva et al. (2009).

O arranjo experimental foi em parcelas subdivididas, sendo as parcelas compostas pelas coberturas vegetais e as subparcelas, pelas plantas medicinais; o delineamento foi blocos casualizados, com cinco repetições. Para a coleta dos dados das plantas e análises microbiológicas do solo, foram usados os mesmos arranjos e repetições, sendo, para a análise microbiológica consideradas duas épocas. Os dados de todas as características avaliadas, das plantas e do solo, foram submetidos à análise de variância. Quando significativos pelo teste $\mathrm{F}$, foram comparados pelo teste de Duncan, à exceção da altura de plantas, avaliadas ao longo do tempo, que foram submetidos à análise de regressão, todos até $5 \%$ de probabilidade.

\section{RESULTADOS E DISCUSSÃO}

As produções de massa seca e fresca das partes aéreas das coberturas vegetais foram diferentes entre espécies (Tabela 1). O feijão de porco apresentou maior acúmulo de biomassa que a mucuna preta, sendo $72 \%\left(18,65 \mathrm{t} \mathrm{ha}^{-1}\right)$ a mais de massa fresca e 58\% (6 tha-1) a mais de massa seca. Esses resultados podem ser explicados pelo fato de o feijão de porco apresentar maior taxa de crescimento inicial, ciclo mais curto, arquitetura ramificada e folíolos largos, o que pode ter contribuído para maior produção de massa seca da parte aérea (Fernandes et al, 1999).

A produtividade de massa seca do feijão de porco obtida neste experimento é superior à observada por Torres et al. (2014), de 3,8 $\mathrm{t} \mathrm{ha}^{-1}$, aos 90 DAS, em Uberaba-MG em Latosso Vermelho distroférrico. Os autores relatam que houve maior incremento na produção de milho utilizando o feijão de porco, do que quando utilizaram-se braquiária, milheto (ADR300), milheto (ADR500), sorgo e crotalária.

Com a maior produção de massa, espera-se que haja incrementos na disponibilidade e ciclagem de nutrientes para as culturas em sucessão; além disso, possibilite maior retenção de água, menor variação na temperatura do solo e maior proteção contra as erosões hídrica e eólica (Lima Filho, et al., 2014). Na análise de Fabaceae herbáceas, Teodoro et al. (2009) observaram que para a produção de massa seca, o feijão de porco se destacou em

Rev. Bras. PI. Med., Campinas, v.18, n.1, supl. I, p.326-335, 2016. 
TABELA 1. Produções de massas frescas e secas das partes aéreas das plantas de mucuna preta e feijão de porco utilizadas na cobertura vegetal do solo antes do cultivo das plantas medicinais.

\begin{tabular}{lcc}
\hline \multirow{2}{*}{ Cobertura Vegetal } & \multicolumn{2}{c}{ Massa da parte aérea (t ha-1) } \\
\cline { 2 - 3 } & Fresca & Seca \\
\hline Mucuna preta & $49,47 \mathrm{~b}$ & $8,37 \mathrm{~b}$ \\
Feijão de porco & $68,12 \mathrm{a}$ & $14,37 \mathrm{a}$ \\
\hline C.V. $(\%)$ & 30,57 & 27,56 \\
\hline
\end{tabular}

*Médias seguidas pelas mesmas letras não diferem entre si, pelo teste $\mathrm{F}$, a $5 \%$ de probabilidade.

relação à mucuna preta, demonstrando maior capacidade de cobrir e melhorar a fertilidade do solo pelo incremento de matéria orgânica. O feijão de porco acumulou 298,90 $\mathrm{kg} \mathrm{ha}^{-1}$ de $\mathrm{N}$ em sua massa, podendo este nutriente ser utilizado pelas culturas sucessoras.

A maior biomassa microbiana, aos 420 DAS, foi observada no sistema de rotação feijão de porco/pimenta rosa, sendo $36 \%$ superior à média do C-BMS dos demais sistemas de cobertura do solo (237 $\mu \mathrm{g} \mathrm{C} \mathrm{g}^{-1}$ de solo) (Tabela 2).

O uso do feijão de porco antecedendo a pimenta rosa incrementou em $130 \%$ o teor de C-BMS, quando comparado à ausência de cobertura do solo. Os demais sistemas em que houve cobertura não diferiram das testemunhas, apesar de ter havido um incremento médio de $56 \%$ no C-BMS com o uso de cultura de cobertura antes da carobinha. Carneiro et al. (2008) observaram incremento de $190 \%$ no C-BMS, em condições de Cerrado, com o uso de feijão de porco como cobertura do solo. Segundo esses autores, esse resultado está associado à maior qualidade bromatológica da fitomassa dessa cultura, bem como, à menor relação $\mathrm{C} / \mathrm{N}$ e maior quantidade de folhas em relação a ramos.

Esse aumento observado no C-BMS com o uso de culturas de cobertura é importante indicador de qualidade do solo, uma vez que a biomassa microbiana condiciona incremento na ciclagem de nutrientes, pois estão imobilizados na fitomassa; após a decomposição são liberados para o solo e a própria biomassa microbiana constitui-se em uma reserva lábil de nutrientes, também rapidamente liberados para o solo, em virtude do baixo tempo de vida dos microrganismos (Carneiro et al., 2008).

Aos 840 DAS, o C-BMS foi em média 152\% superior ao de 420 DAS, não havendo diferença entre os tratamentos com e sem cultura de cobertura (Tabela 2). Esses resultados podem ser explicados pelo fato de a segunda coleta ter sido realizada dois anos após o revolvimento do solo, o que pode ter contribuído para esse incremento em função da maior estabilização do sistema solo. O revolvimento do solo contribui para importante redução na quantidade e diversidade de microrganismos do solo; de forma inversa, a adoção de práticas de manejo conservacionistas que condicionam aumentos em atributos biológicos associados à biomassa microbiana proporcionam incrementos na ciclagem de nutrientes e energia no sistema solo (Cunha et al., 2011).

Entre as sucessões estudas, houve

TABELA 2. Carbono da biomassa microbiana do solo* (C-BMS) em função da ausência e presença de culturas de cobertura dentro de cada época de avaliação.

\begin{tabular}{|c|c|c|}
\hline \multirow{2}{*}{ Cobertura do solo/sucessão } & \multicolumn{2}{|c|}{ 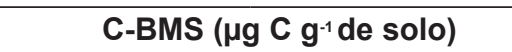 } \\
\hline & 420 DAS & 840 DAS \\
\hline Feijão de porco/carobinha & $253 a b$ & $497 \mathrm{a}$ \\
\hline Feijão de porco/Vinagreira & $241 a b$ & $505 a$ \\
\hline Feijão de porco/pimenta rosa & 323 a & $647 \mathrm{a}$ \\
\hline Mucuna/carobinha & $248 a b$ & $614 a$ \\
\hline Mucuna/Vinagreira & $215 \mathrm{bc}$ & $574 a$ \\
\hline Mucuna/pimenta rosa & $229 a b$ & 594 a \\
\hline Carobinha & $161 \mathrm{bc}$ & $488 \mathrm{a}$ \\
\hline Vinagreira & $216 \mathrm{bc}$ & $630 a$ \\
\hline Pimenta rosa & $140 \mathrm{c}$ & 559 a \\
\hline Média & 225,11 & 567,56 \\
\hline C.V.(\%) & 24,0 & 26,0 \\
\hline
\end{tabular}

Médias seguidas da mesma letra minúscula na coluna, não diferem entre si pelo teste Duncan, a $5 \%$ de probabilidade. * Análises feitas no laboratório de solos da Embrapa Agropecuária Oeste, Dourados-MS

Rev. Bras. PI. Med., Campinas, v.18, n.1, supl. I, p.326-335, 2016. 
diferença na respiração microbiana $\left(\mathrm{C}-\mathrm{CO}_{2}\right)$ (Tabela 3) entre feijão de porco/pimenta rosa e mucuna/ pimenta rosa, com maior perda de $\mathrm{CO}_{2}$ na primeira sucessão. Esse resultado pode ser consequência do maior teor de C-BMS, que em função do seu metabolismo, libera maior quantidade de $\mathrm{CO}_{2}$. A maior liberação de $\mathrm{CO}_{2}$ geralmente está associada à maior atividade biológica, que, por sua vez, está relacionada diretamente à quantidade de $\mathrm{C}$ lábil no solo. Entretanto, elevados valores de respiração podem, a curto prazo, significar liberação de nutrientes e, a longo prazo, perda de carbono orgânico para atmosfera (Parkin et al., 1996).

$\mathrm{O} \mathrm{qCO}_{2}$ é importante indicador da eficiência da biomassa microbiana. As sucessões foram diferentes apenas aos 420 DAS (Tabela 3), com os maiores valores observados quando se cultivou pimenta rosa e carobinha sem cobertura. Valores elevados de $\mathrm{qCO}_{2}$ implicam em menor eficiência do C-BMS, em função de alguma condição de estresse ou de desequilíbrio que favorece maior perda de $\mathrm{CO}_{2}$ por unidade microbiana, ou seja, menor eficiência do C-BMS (Odum, 1969; Anderson \& Domsch, 1993). A ausência de cobertura do solo implicou em elevadas perdas de carbono do solo na forma de $\mathrm{CO}_{2}$, contribuindo para menor sustentabilidade do sistema.

À medida que a biomassa microbiana se torna mais eficiente na utilização de recursos do ecossistema, menos $\mathrm{CO}_{2}$ é perdido pela respiração e maior proporção de carbono é incorporada aos tecidos microbianos, o que resulta em diminuição do $\mathrm{qCO}_{2}$, e consequentemente, agroecossistemas mais estáveis (Cunha et al., 2011).

Aos 840 DAS, logo após a colheita das plantas medicinais (Tabela 3) já não havia resíduos das plantas de cobertura, não sendo possível observar os efeitos delas sobre o C-BMS, de forma que as modificações por meio da liberação de compostos orgânicos depositados na rizosfera pelas plantas medicinais constituiu fator favorável para o desenvolvimento e crescimento de diferentes grupos de microrganismos, implicando em maior eficiência da biomassa microbiana (Cunha et al., 2011).

As alturas das plantas de pimenta rosa foram influenciadas pela interação coberturas vegetais e épocas de avaliação (Figura 2). As maiores alturas máximas foram observadas utilizando-se a cobertura de feijão de porco $(191,13$ $\mathrm{cm})$ seguida pela mucuna preta $(190,94 \mathrm{~cm})$, aos 490 DAT. Houve incremento de $19,36 \mathrm{~cm}$ com a utilização do feijão de porco e $20,16 \mathrm{~cm}$ com a utilização da mucuna preta em relação à testemunha (Figura 2). Isso provavelmente ocorreu porque a cobertura vegetal, em forma de palhada, induziu mudanças na aeração e na capacidade de retenção da água, proporcionando aumento da atividade dos processos microbianos no solo, em resposta à decomposição orgânica (Lima filho et al., 2014), processo esse que foi favorecido pelo fato de o ciclo vegetativo da pimenta rosa ser longo, resultando em maior crescimento da planta.

As plantas de vinagreira e carobinha tiveram suas alturas influenciadas pelas épocas de avaliações, alcançando altura máxima de 125 $\mathrm{cm}$ aos 180 DAT e de $34,22 \mathrm{~cm}$, aos 440 DAT (Figura 2). Na literatura há trabalhos que relatam resultados diferentes sobre a influência dos adubos verdes na altura de plantas, pois enquanto em alguns houve influência (Valicheski et al., 2012), em outros não houve (Lázaro et al., 2013). Isso, porque o crescimento é predeterminado pelo genótipo das espécies, sendo a altura de plantas pouco influenciada pelos fatores do ambiente. Contudo, há espécies como a pimenta rosa que possuem alta plasticidade adaptativa, moldando sua forma

TABELA 3. Respiração $\left(C-\mathrm{CO}_{2}\right)$ e quociente microbiano $\left(q \mathrm{CO}_{2}\right)$ no solo em função da presença e ausência de culturas de cobertura, dentro de cada época de avaliação.

\begin{tabular}{|c|c|c|c|}
\hline \multirow[t]{2}{*}{ Cobertura do solo/sucessão } & \multirow{2}{*}{$\begin{array}{c}\mathrm{C}-\mathrm{CO}_{2} \\
\left(\mu \mathrm{g} \mathrm{g}^{-1} \mathrm{dia}^{-1} \mathrm{de} \mathrm{C}-\mathrm{CO}_{2} \text { no solo }\right)\end{array}$} & \multicolumn{2}{|c|}{$\begin{array}{c}q \mathrm{CO}_{2} \\
\left(\mu \mathrm{g} \mathrm{CO} / \mu g \mathrm{C}_{\text {mic }} \mathrm{h}^{-1}\right)\end{array}$} \\
\hline & & 420 DAS & 840 DAS \\
\hline Feijão de porco/carobinha & $9,7 a b$ & $18,9 \mathrm{bA}$ & $6,9 \mathrm{aA}$ \\
\hline Feijão de porco/Vinagreira & $6,9 a b$ & 12,7 bcA & 8,0 aA \\
\hline Feijão de porco/pimenta rosa & $12,2 \mathrm{a}$ & 11,2 bcA & $8,2 \mathrm{aA}$ \\
\hline Mucuna/carobinha & $7,9 a b$ & $6,7 \mathrm{cA}$ & $7,4 \mathrm{aA}$ \\
\hline Mucuna/Vinagreira & $6,3 \mathrm{~b}$ & $7,9 \mathrm{cA}$ & $5,8 \mathrm{aA}$ \\
\hline Mucuna/pimenta rosa & $8,3 a b$ & 14,2 bcA & $5,5 \mathrm{aB}$ \\
\hline Carobinha & $9,6 a b$ & $31,6 \mathrm{aA}$ & $6,8 \mathrm{aB}$ \\
\hline Vinagreira & $6,1 \mathrm{~b}$ & 10,0 bcA & $4,1 \mathrm{aA}$ \\
\hline Pimenta rosa & $10,9 a b$ & 40,7 aA & $5,4 \mathrm{aB}$ \\
\hline C.V. (\%) & 37,0 & 40,0 & 39,0 \\
\hline
\end{tabular}

Médias seguidas da mesma letra minúscula nas colunas e maiúscula nas linhas, não diferem entre si pelo teste Duncan, a 5\% de probabilidade.

Rev. Bras. PI. Med., Campinas, v.18, n.1, supl. I, p.326-335, 2016. 

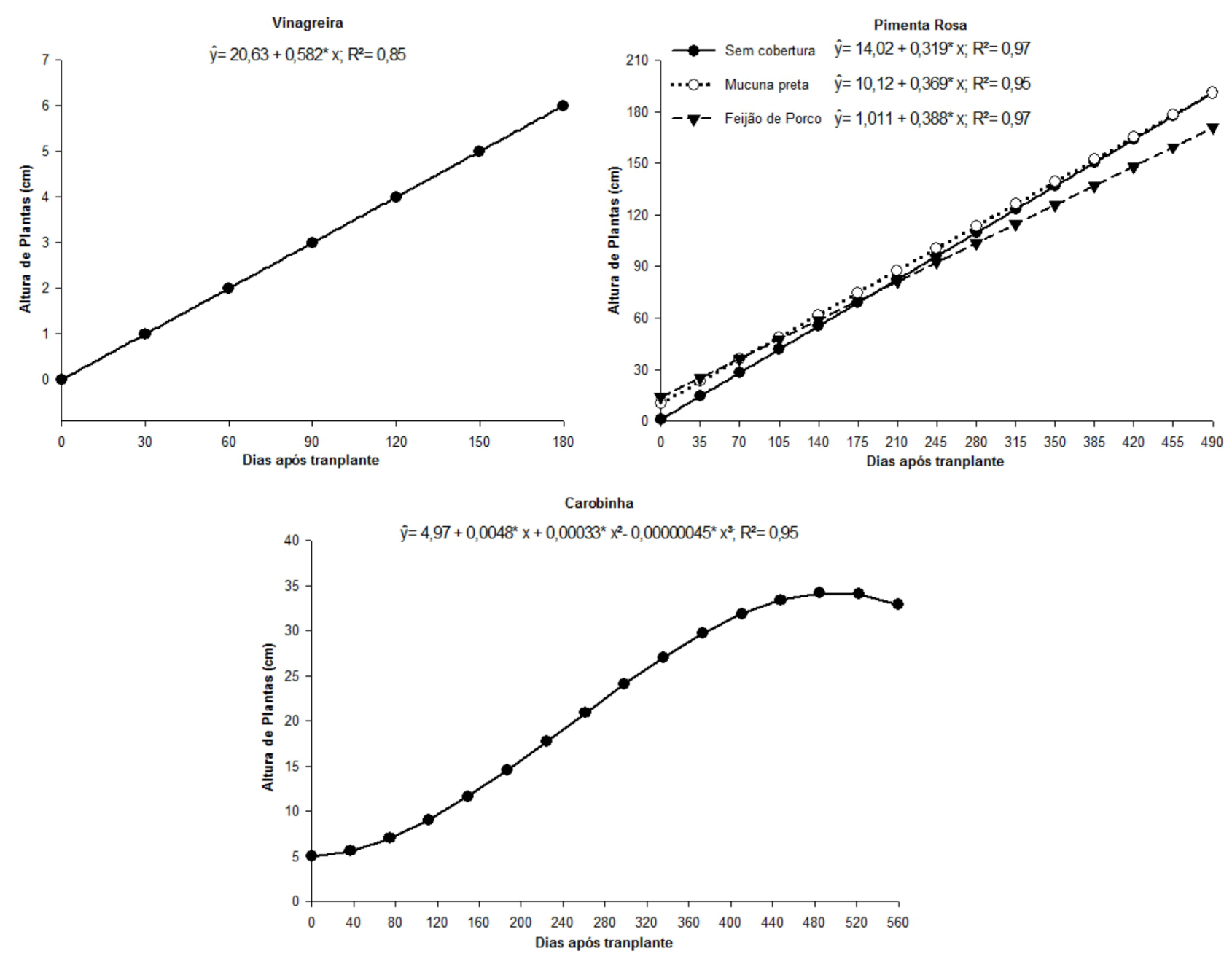

FIGURA 2. Altura de plantas de vinagreira, pimenta rosa e carobinha cultivadas em sucessão à mucuna preta e feijão de porco. As medias das coberturas vegetais para vinagreira e carobinha foram agrupadas. * Significativo a $5 \%$ de probabilidade.

de crescimento conforme o ambiente em que está se desenvolvendo.

As produções de massa seca de caules, folhas e frutos da vinagreira foram maiores quando se usou a cobertura vegetal (Tabela 4), independente da espécie. Houve ganho médio de massa seca de $193 \%$ para caule, $173 \%$ para folha e $150 \%$ para frutos, comparando-se com a testemunha. Esse resultado deve-se, dentre outros, ao fato de as coberturas vegetais, mucuna preta e de feijão de porco, possuírem autossuficiência em nitrogênio e um sistema radicular profundo e ramificado, capaz de extrair nutrientes das camadas mais profundas do solo Forneceram grandes quantidades de matéria orgânica ao solo, melhorando suas características físicas, químicas e biológicas, contribuindo para um aumento significativo na produção (Leite et al., 2010; Teodoro et al., 2011).

A área foliar da vinagreira não variou em função da cobertura vegetal do solo (Tabela 4), sendo a média geral de $4.039,74 \mathrm{~cm}^{2} /$ planta. A falta de efeito significativo sobre a área foliar pode estar relacionada ao fato de ocorrer nessa espécie início da abscisão foliar na época de produção dos frutos, sendo sucedido pela senescência da planta quando as sementes estão em estádio de maturidade fisiológica, o que pode ter diminuído a área foliar pela murcha das folhas e diminuído as diferenças entre os tratamentos. Provavelmente, teria sido mais apropriado colher as plantas inteiras antes do florescimento, quando havia maior uniformidade de parte aérea entre elas.

As folhas e frutos da pimenta rosa tiveram massas secas maiores quando se usou a cobertura vegetal do solo, independente da espécie (Tabela 5). Observou-se que houve aumento de 202\% (2,95 t ha-1 $^{-1}$ na produção de folhas utilizando mucuna preta em relação à ausência do uso. Esse acréscimo está associado ao aumento da disponibilidade de nutrientes por meio da decomposição da matéria orgânica e pela ciclagem de nutrientes que essas coberturas vegetais proporcionam, assim como

Rev. Bras. PI. Med., Campinas, v.18, n.1, supl. I, p.326-335, 2016. 
TABELA 4. Produções de massas secas e área foliar de vinagreira cultivadas em sucessão à mucuna preta e feijão de porco.

\begin{tabular}{|c|c|c|c|c|}
\hline \multirow{2}{*}{ Cobertura vegetal } & \multicolumn{3}{|c|}{ Massa seca $\left(t^{\prime} a^{-1}\right)$} & \multirow{2}{*}{$\begin{array}{l}\text { Área foliar } \\
\left(\mathrm{cm}^{2} / \text { planta }\right.\end{array}$} \\
\hline & Caule & Folha & Frutos & \\
\hline Mucuna preta & $10,70 \mathrm{a}$ & $6,68 \mathrm{a}$ & $10,19 a$ & $4.129,46$ \\
\hline Feijão de porco & 11,83 a & $7,20 \mathrm{a}$ & $10,72 a$ & $5.034,28$ \\
\hline Testemunha & $5,82 \mathrm{~b}$ & $4,01 \mathrm{~b}$ & $6,94 \mathrm{~b}$ & $2.955,48$ \\
\hline C.V. $(\%)$ & 11,94 & 7,02 & 17,64 & 38,05 \\
\hline
\end{tabular}

Medias seguidas pela mesma letra, nas colunas, não diferem entre si pelo teste Duncan, a $5 \%$ de probabilidade.

pela melhoria física do solo pela adição da matéria orgânica ao solo. Esses resultados corroboram com os de Delarmelinda et al. (2010), que relatam aumento da matéria orgânica no solo com o uso coberturas vegetais, e também nas características químicas do solo.

Destaca-se o incremento que as coberturas vegetais proporcionaram à produção de massa seca dos frutos da pimenta rosa, por serem esses órgãos de interesse comercial. O aumento de 533\% com o uso de feijão de porco e $450 \%$ com o uso de mucuna preta demonstra a importância do uso dessas coberturas vegetais como adubo verde, especialmente, quando resultarem em incremento na produção dos órgãos de interesse econômico.

As produções de massa seca de rizóforos, caules e folhas e área foliar da carobinha foram influenciadas significativamente pelas coberturas vegetais do solo (Tabela 6). As maiores produções de rizóforo, caules e folhas foram obtidas com a utilização do feijão de porco, embora, no caso das massas secas de caules e folhas, não terem sido diferentes de onde não se usou cobertura. Observa-se que houve aumentos de produções de $161 \%$ para rizóforos, $238 \%$ para caules e $216 \%$ para folhas em comparação com a utilização da cobertura mucuna preta. A área foliar foi maior quando se usou o feijão de porco ou não se usou cobertura vegetal do solo. Esse fato pode ser explicado pelas características adaptativas da carobinha ao seu ambiente natural, que possui baixo teor de matéria orgânica e nutrientes, como é o caso dos solos do Cerrado.

A produção de massa seca de raiz não foi influenciada pelas coberturas vegetais (Tabela 6). Isso demonstra que os caracteres genéticos da espécie determinaram o desenvolvimento da planta, especialmente, do sistema subterrâneo e, portanto, para essa espécie, pequenas alterações no solo vão influenciar pouco na produção de massa seca de raiz. Resultado semelhante foi constado por Sangalli et al. (2011), em que a produção de raízes da carobinha não foi influenciada pela cobertura do solo com cama de frango.

O fato de a planta de carobinha ter produzido sistema radicular mais desenvolvido do que o caule (Tabela 6) comprova a característica própria de plantas do Cerrado, que investem mais energia no sistema radicular (Sangalli et al., 2011). Esse fato está relacionado com a distribuição diferencial de fotoassimilados na planta que determina os padrões de crescimento, que deve ser equilibrado entre a parte aérea, responsável pela produtividade fotossintética, e a raiz, que é a principal fonte de absorção de água e minerais (Taiz \& Zeiger, 2013). Cabe destacar a importância dessa característica, por ser a raiz o órgão de interesse econômico dessa espécie.

Os resultados para carbono na biomassa microbiana, para respiração e para o quociente microbiano do solo foram influenciados diferentemente pela cobertura dos resíduos vegetais, dentro de cada característica avaliada e da época de avaliação. As áreas foliares, as alturas de plantas e as massas secas das plantas das espécies medicinais em estudo apresentaram respostas produtivas diferentes em relação aos resíduos vegetais utilizados na cobertura do solo.

TABELA 5. Produções de massas secas e área foliar de pimenta rosa cultivadas em sucessão a mucuna preta e feijão de porco.

\begin{tabular}{lcccc}
\hline \multirow{2}{*}{ Cobertura Vegetal } & \multicolumn{3}{c}{ Massa seca (t ha-1) } & Área foliar \\
\cline { 2 - 4 } & Caule & Folha & Frutos & (cm²/planta) \\
\hline Mucuna preta & 2,78 & $5,82 \mathrm{a}$ & $0,27 \mathrm{a}$ & $5.385,50$ \\
Feijão de porco & 3,88 & $4,36 \mathrm{ab}$ & $0,32 \mathrm{a}$ & $5.200,17$ \\
Testemunha & 2,88 & $2,87 \mathrm{~b}$ & $0,06 \mathrm{~b}$ & $3.383,32$ \\
\hline C.V. $(\%)$ & 38,83 & 23,58 & 51,69 & 41,86 \\
\hline
\end{tabular}

Medias seguidas pela mesma letra coluna não diferem entre si pelo teste Duncan, a $5 \%$ de probabilidade.

Rev. Bras. PI. Med., Campinas, v.18, n.1, supl. I, p.326-335, 2016. 
TABELA 6. Produções de massas secas e área foliar de carobinha cultivadas em sucessão à mucuna preta e feijão de porco.

\begin{tabular}{|c|c|c|c|c|c|}
\hline \multirow{2}{*}{ Cobertura Vegetal } & \multicolumn{4}{|c|}{ Massa seca (kg ha-1) } & \multirow{2}{*}{ Área foliar $\left(\mathrm{cm}^{2} /\right.$ planta } \\
\hline & Raiz & Rizóforo & Caule & Folha & \\
\hline Mucuna preta & 151,37 & $159,22 \mathrm{c}$ & $75,15 b$ & $101,97 b$ & $985,47 \mathrm{~b}$ \\
\hline Feijão de porco & 232,12 & $256,40 \mathrm{a}$ & $179,18 \mathrm{a}$ & 220,66 a & $1232,37 \mathrm{a}$ \\
\hline Testemunha & 223,26 & $209,83 \mathrm{~b}$ & 137,36 a & 220,34 a & 1347,87 a \\
\hline C.V. (\%) & 22,74 & 12,02 & 24,39 & 9,22 & 11,10 \\
\hline
\end{tabular}

Medias seguidas pela mesma letra coluna não diferem entre si pelo teste Duncan, a $5 \%$ de probabilidade.

\section{CONCLUSÕES}

O uso de cobertura do solo incrementou o carbono da biomassa microbiana do solo, notadamente pelo uso de feijão de porco. Por outro lado, a ausência de cobertura do solo implicou em elevadas perdas de carbono do solo na forma de $\mathrm{CO} 2$, refletindo em menor eficiência da biomassa microbiana e menor sustentabilidade no primeiro ano de implantação do sistema. As produções de massas secas de folhas, caules e frutos de vinagreira e de massas secas de folhas e frutos da pimenta rosa foram maiores quando cultivadas em sucessão às coberturas vegetais do solo, independente da espécie utilizada. As produções da carobinha foram semelhantes quando cultivadas em áreas com ou sem culturas antecessoras. Visando à maior produtividade da vinagreira e pimenta rosa, são indicadas as culturas antecessoras feijão de porco e mucuna preta.

\section{AGRADECIMENTOS}

Este trabalho foi apoiado com recursos financeiros e bolsas pela Fundação de Apoio ao Desenvolvimento do Ensino, Ciência e Tecnologia do Estado de Mato Grosso do Sul (FUNDECT), Conselho Nacional de Desenvolvimento Científico e Tecnológico (CNPq) e Coordenação de Aperfeiçoamento de Pessoal de Nível Superior (CAPES).

\section{REFERÊNCIAS}

ANDERSON, J.P.E.; DOMSCH, K.H. The metabolic quotient of $\mathrm{CO}_{2}\left(q \mathrm{CO}_{2}\right)$ as a specific activity paramenter to assess the effects of environmental condition, such as $\mathrm{pH}$, on the microbial of forest soil. Soil Biology and Biochemistry, v.25, n.3, p.393-395, 1993.

BERTONI, B.W. et al. Genetic diversity in natural populations of Jacaranda decurrens Cham. determined using RAPD and AFLP markers. Genetics and Molecular Biology, v.33, n.3, p.532-538, 2010.

CARNEIRO, M.A.C. et al.. Produção de fitomassa de diferentes espécies de cobertura e suas alterações na atividade microbiana de solo de Cerrado. Bragantia, v.67, n.2, p.455-462, 2008.

CARVALHO, C.A. et al. Atividade antioxidante de Jacaranda decurrens Cham., Bignoniaceae. Revista Brasileira de Farmacognosia, v.19, n.2, p.592-598, 2009.

CUNHA, E.Q. et al. Sistemas de preparo do solo e culturas de cobertura na produção de feijão e milho. II Atributos biológicos do solo. Revista Brasileira de Ciência do Solo, v.35, n.2, p.603-611, 2011.

DELARMELINDA, E.A. et al. Adubação verde e alterações nas características químicas de um Cambissolo na região de Ji-Paraná-RO. Acta Amazonica, v.40, n.3, p.625-628, 2010.

FARIAS, R.; PROENÇA, C. Jacaranda decurrens subsp. symmetrifoliolata (Bignoniaceae), novo táxon para o bioma cerrado. Boletim do Herbarium Bradeanum, v.11, n.1, p.5-9, 2003.

FENNER, R. et al. Plantas utilizadas na medicina popular brasileira com potencial atividade antifúngica. Brazilian Journal of Pharmaceutical Sciences, v.42, n.3, p.369394, 2006.

FERNANDES, M. F.; BARRETO, A. C.; EMÍDIO FILHO. J. Fitomassa de adubos verdes e controle de plantas daninhas em diferentes densidades populacionais de leguminosas. Pesquisa Agropecuária Brasileira, v.34, n.9, p.1593-1600, 1999.

FREIRES, I.A. et al. Atividades antibacteriana e antiaderente in vitro de tinturas de Schinus terebinthinfolius (aroeira) e Solidago microglossa (arnica) frente a bactérias formadoras do biofilme dentário. Odontologia ClínicoCientífica, v.9, n.2, p.139-143, 2010.

FREITAS, N.M. et al. Avaliação fitoquímica e determinação de minerais em amostras de Hibiscus sabdariffa $L$ (vinagreira). Cadernos de Pesquisa, v.20, n.3, p.6572, 2013.

GALON, L. et al. Efeito de herbicidas na atividade microbiana do solo cultivado com diferentes genótipos de cana-de-açúcar. Revista Brasileira de Herbicidas, v.13, n.1, p.47-57, 2014.

GOMES, S.S. et al. Bioindicadores de qualidade do solo cultivado com milho em sucessão a adubos verdes sob bases agroecológicas. Revista de la Facultad de Agronomía, v.114, n.1, p.30-37, 2015.

JOLY C.A. et al. Diagnóstico da pesquisa em biodiversidade no Brasil. Revista USP, Brasil, n.89, p.114-133, 2011. ISSN 2316-9036. Disponível em: <http://www.revistas. usp.br/revusp/article/view/13873/15691>. Acesso em: 28 jan. 2016.

KOTTEK, M. et al. World map of the Köppen-Geiger climate classification updated. Meteorologische

Rev. Bras. PI. Med., Campinas, v.18, n.1, supl. I, p.326-335, 2016. 
Zeitschrift, v.15, n.3, p.259-263, 2006.

LÁZARO, R.L. et al. Produtividade de milho cultivado em sucessão à adubação verde. Pesquisa Agropecuária Tropical, v.43, n.1, p.10-17, 2013.

LEITE, L.F.C. et al. Decomposição e liberação de nutrientes de resíduos vegetais depositados sobre Latossolo Amarelo no Cerrado Maranhense. Revista Ciência Agronômica, v.41, n.1, p.29-35, 2010.

LIMA FILHO, O.F. et al. Adubação verde e plantas de cobertura no Brasil: fundamentos e prática. 1 ed. Brasília, DF: Embrapa, 2014. 507p.

MACIEL, M.J. et al. Avaliação do extrato alcoólico de hibisco (Hibiscus sabdariffa L.) como fator de proteção antibacteriana e antioxidante. Revista do Instituto Adolfo Lutz, v.71, n.3, p.462-470, 2012.

ODUM, E.P. The Strategy of ecosystem development. Science, v.164, n. 3877, p.262-270, 1969.

PARKIN, T.B. et al. Field and Laboratory Tests of Soil Respiration. In: DORAN, J.W.; JONES, A.J. (Ed.). Methods for assessing soil quality, WI. 1996. $p$ 231-245.

RAMOS, D.D. et al. Atividade antioxidante de rosela em função do espaçamento entre plantas e da adubação orgânica. Ciência Rural, v.41, n.8, p.1331-1336, 2011.

SANGALLI, A. et al. Desenvolvimento e produção da carobinha (Jacaranda decurrens Cham. subsp. symmetrifoliolata Farias \& Proença) cultivada sob dois arranjos de plantas, com ou sem cobertura de cama-de-frango no solo. Revista Brasileira de Plantas Medicinais, v.13, n.4, p.439-446, 2011.

SANTOS, A.C.A. et al. Efeito fungicida dos óleos essenciais de Schinus molle L. e Schinus terebinthifolius Raddi, Anacardiaceae, do Rio Grande do Sul. Revista Brasileira de Farmacognosia, v.20, n.2, p.154-159, 2010a.

SANTOS, S.B et al. Comparação da eficácia da aroeira oral (Schinus terebinthifolius Raddi) com omeprazol em pacientes com gastrite e sintomas dispépticos: estudo randomizado e duplo-cego. Gastroenterologia e Endoscopia Digestiva, v.29, n.4, p.118-125, 2010b.

SILVA, A.A. et al. Desempenho agronômico e econômico do milho irrigado em sucessão a espécies invernais de cobertura de solo e/ou para produção de grãos. Ciência Rural, v.38, n.3, p.620-627, 2008.

SILVA, F.C. et al. Análises químicas para avaliação da fertilidade do solo. In: SILVA, F.C. (Org.). Manual de análises químicas de solos, plantas e fertilizantes. 2. ed. Brasília: Embrapa Comunicação para Transferência de Tecnologia, 2009. p.107-190.

TAIZ, L. ZEIGER, E. Fisiologia vegetal. 5. ed. Porto Alegre: Artmed, 2013. 918p.

TAVARES JUNIOR, J.B. et al. Produção de fabaceas para adubação verde no agreste paraibano. Journal of Biology \& Pharmacy and Agricultural Management, v.11, n.1, p.47-58, 2015.

TEODORO, R.B. et al. Aspectos agronômicos de leguminosas para adubação verde no cerrado do alto Vale do Jequitinhonha. Revista Brasileira de Ciência do Solo, v.35, n.2, p.635-643, 2011.

TEODORO, R.B. et al. Acúmulo de fitomassa e ciclagem de nutrientes por leguminosas herbáceas no município de Tumarina - MG. Cadernos de Agroecologia, v.4, n.2, p.1511-1514, 2009

TORRES, J.L.R. et al. Cultivo de feijão e milho em sucessão a plantas de cobertura. Revista Caatinga, v.27, n.4, p.117-125, 2014.

VALICHESKI, R.R. et al. Desenvolvimento de plantas de cobertura e produtividade da soja conforme atributos físicos em solo compactado. Revista Brasileira de Engenharia Agrícola e Ambiental, v.16, n.9, p.969977, 2012.

YEOMANS, J.C.; BREMNER, J.M. A rapid and precise method for routine determination of organic carbon in soil. Communications in Soil Science and Plant Analyses, v.19, p.1467-1476, 1989.

VANCE, E.D.; et al., An extraction method for measuring soil microbial biomass. Soil Biology and Biochemistry, v.19, n.6, p.703-707, 1987.

ZATTA, D.T. et al. Estudo da Atividade Antibacteriana contra cepas de Pseudomonas aeruginosa e da Toxicidade Aguda das folhas da Jacaranda decurrens. Latin American Journal of Pharmacy, v.28, n.4, p.485-489, 2009. 